\title{
Homestay: guest perception towards indigenous food \& beverage of Sikkim
}

\section{Sanjiv Kumar Sharma ${ }^{1}$, Suresh.N ${ }^{2}$, Praveen Rizal ${ }^{3}$}

1 Ph.D. Research Scholar and Assistant Professor, School of Hospitality \& Tourism Studies, Shri Ramasamy Memorial University Sikkim, India

${ }^{2}$ Associate Professor, School of Hospitality \& Tourism Studies, Shri Ramasamy Memorial University Sikkim, India ${ }^{3}$ Associate Professor, Department of Economics, Shri Ramasamy Memorial University Sikkim, India

${ }^{1}$ dr.sanjivkunnu@gmail.com

Received: 18/11/2020 Revised: 27/11/2020 Accepted: 5/12/2020 DOI: https://doi.org/10.31559/IJHTS2020.1.2.3

\begin{abstract}
:
The present study focuses on a homestay, where researchers assess the level of awareness about indigenous foods and beverages and the preference of indigenous foods of Sikkim among the homestay visitors/guests. Sikkim has different communities that run homestay which serves several indigenous foods and beverages. The current study is based on the primary data, collected through Google form (online survey due to COVID-19 pandemic) between the months of July-August 2020. Secondary data are not used for this study. This study shows Sikkim has their cooking style, ingredients, and garnishing of cooked food and beverages. However, most of the guests/visitors were unaware of the various foods, so promotional activities are needed here by The Tourism \& Civil Aviation Department Government of Sikkim (hospitality/homestay division) and stakeholders. The study offers recommendations, including growing awareness, promotion, and preference of indigenous food and beverages among the homestay visitors/guests. "The present study lies in the stability of finding such literature" which is directly related to the findings. Tata Group-indorsed hospitality main Indian Hotels Company Ltd (IHCL) has arrived at the homestay division with the brand Ama Trails and Stays wherein it will enter into a management contract with nine (9) heritage bungalows with Tata Coffee in Coorg and Chikmagalur.
\end{abstract}

Keywords: Indigenous; Foods and Beverages; Guest; Homestay; Sikkim.

\section{Introduction}

A homestay is a popular form of hospitality and lodging where guests/visitors share a residence with a local of the city or village to which they are traveling. Homestays offer several advantages such as local hospitality and many more activities. Homestay is a really new trend and idea, which is still in a transformative phase on the globe, and India can set a homestay environment as a major aspect. Homestays are the eco-tourism model in India, and its outmost surroundings. Eco-tourism is a matchless turn to the homestay idea that many overseas visitors/guest catches very attractive. In Sikkim, a State of India, has different communities who serves several indigenous food and beverages at their own homestay, drinks are alcoholic and rice beer. The well-known indigenous beverage of Sikkim is Tongba or Chaang, they usually offer it to their guests. All the foods have their own identity and uniqueness in the homestay of Sikkim, therefore here personalise service to homestays up the mark, which any star hotel and restaurant simply cannot repeat the same.

Sikkim is a hilly and organic state of India (Bharat) with an area of $7096 \mathrm{sq} . \mathrm{km}$ and altitudes reaching from $300 \mathrm{~m}$ to $8500 \mathrm{~m}$. Sikkim is located in the Eastern Himalayas between 27o 5' to 28o 9' North Latitude and 87o 59' to 88o 56' East Longitude. The state comprises four districts: North, East (Capital of Sikkim Gangtok), South and West(Jyoti Prakash Tamang et al., 2007).The Sikkim state accommodates three traditional groups Lepcha, Bhutia and Nepali. Societies of various hues mingle freely to constitute a uniform blend of activities. The Hindu Temples exist with Buddhist Monasteries, Churches, Mosque and Gurudwara. These Cultures have formed a typical Sikkimese Culture that includes all ways and walks of life, but has also managed to preserve their own identity. These also can be seen within the various places of Worship, Festivals and Cultural dances that are celebrated throughout the year(Tourism \& Civil Aviation Department Sikkim, n.d.). 
Indigenous Peoples and food structures grip resources of awareness from long-evolved cultures and shapes of living in local ecosystems $(\mathrm{V}, 2007)$. Indigenous food is founded on the research of cooking recipes with products taken from natural species of an exact region. Indigenous foods are cooked by using indigenous ingredients.

\section{Glimpse of Homestay}

In India Athithi Devo Bhavah meaning the guest is God. The Indian tourism industry and homestays have become a sustainable choice for both travellers and its owners alike. For the homestay guest, home away from home that is well placed into the greens or high up in the hills, in the outmost localities. Therefore the homestay host family members generates well-paid income source. The core attraction for homestays is that, host family members permit guest/visitors to taste the local flavour (sowing and harvesting the local crop) of a destination at an affordable rate (in terms of true, home-cooked indigenous food and lifestyle of the locals). Even, The Government of India (Ministry of tourism) has hassle-free the licensing rules for converting their home into certified/approved homestay. To bridge the growing demand-supply of day by day gap, the Government of India (MoT) has delivered several incentives to homestays sectors(Puri, 2018). Tata Group-indorsed hospitality main Indian Hotels Company Ltd (IHCL) has arrived the homestay division with the brand Ama Trails and Stays wherein it will enter into management contract with nine (9) heritage bungalows with Tata Coffee in Coorg and Chikmagalur. There ideas to add two of its own bungalows in Goa by mid-next year under the AMA umbrella. As specified by professionals, while the homestay portion is still at a beginning stage, India is being supported as a top goal for homestay as sightseers experience local hospitality flavours and culture at moderate rates. Mr. Puneet Chawla, Managing Director and CEO of IHCL, said: "With India's rich diversity, we are confident that we will be able to scale this product (homestays) to the first 100 units before the end of 2020 and bring distinctive offerings for our guests across the Indian sub-continent." He further added that the demand growth is outpacing supply in the Indian hospitality sector at present in both luxury and upscale properties(Bureau, 2019).

\section{Review of Literature}

At homestay and other hospitality divisions in Sikkim, host family's welcome guests by offering Khada (traditional scarf), all the communities of homestay have different patterns and color of Khada to offer guests during check-in time. Offering Khada is very important and divine for them. Different communities serve various indigenous beverages at their own homestay, drinks are alcoholic and rice beer. The well-known indigenous beverage of Sikkim is Tongba or Chaang, they usually offer it to their guests. They also welcome guests by performing their traditional dances and culture on request (Chaudhary \& Lama, 2014).

Incredible India Bed \& Breakfast (B\&B) / Homestay Scheme offers to all tourists/guest an opportunity to stay with an Indian host family members and enjoy the warm local hospitality and get a taste of Indian culture and various indigenous food and beverage (Chhurpi, Dal Bhat, Selroti, Sinki, Thukpa, Kodo ko Roti, Chaang, Gundruk, Tea and many more) in a clean and affordable place (Jyoti P Tamang et al., 1988). Home stays are a pleasing form of accommodation which provides all the unique facilities \& services akin to what you have at your own house (S. Sharma \& Goswami, 2020).

Indigenous food and beverage can be categorized into (2) two (a) Fermented (b) Non-Fermented.

There are a number of foods and beverages served by host (homestay) as a main course, side dish, curry, soup, alcoholic beverage, snacks, edible plants and many more food condiments(A. Sharma \& Prabir, 2015).

Every food cooked and served by the different ethnic communities in the homestay of Sikkim, foods are unique and unmatched, due to wide geographical location, food preference, climatic, soil conditions, and availability of plant and animal sources. Rice or maize is a staple food in Sikkim, and alcoholic beverages locally called Kodo KO Jaanr or Chyang made from fermented finger millets or barley are common in Sikkim. Yak milk and its products are popular(Jyoti et al., 2010).

The individuals from neighbouring nations like Nepal, Tibet and Bhutan who encapsulated a few networks. So after some time the cooking and food in Sikkim has become a combination of different societies. Each network in Sikkim has their own cooking and service style at homestay. Where a host family cooks food and serves to the guest, which gives a different indigenous food of Sikkim(Raj, 2020).

\section{Selected Indigeous Food and Beverage of Sikkim}

Sikkim is the place of the Lepchas, Who were the original residents of the State. Since 1600s there has been continuous immigration of the people from neighbouring state of India and other countries like Nepal, Tibet and Bhutan who had several communities within themselves. Therefore over the period of time foods and beverages (cuisine) in Sikkim has become a fusion of various cultures and communities. Being a multi indigenous mix every community in Sikkim has their own cooking style and ingredients (Sikkimese foods and beverages). It is the best to experience them in the homestay of Sikkim, where host family members cook and serves indigenous food to the guest.

Shiva and Radha Gurung, run an enchanting homestay called Daragaon Town Retreat in West Sikkim. Stated, Great cheddar begins with great milk. The crude milk matures over a couple of hours, transforming into runny yogurt. This excellent margarine bears an unusual, practically animating dairy taste. The majority of this 
margarine before long proselytes into ghee, and remaining buttermilk, known as Mahee in the neighbourhood, is the wellspring of Chhurpi.

Chhurpi hung together on twine for the excited adventurer. While it might be the size of a normal chomp, this conventional hard cheddar, made with yak or cow milk, can't be bitten down effectively, Chhurpi can be devoured new. Chhurpi is a type of protected milk, and it is normally bitten for a considerable length of time, if not hours. This protein-rich cheddar makes for an extraordinary snack for herders and explorers, as they navigate rocky landscapes.

Fresh youthful and delicate Chhurpi to add richness to delicious chutneys. Receiving group of homestay heats up a tomato till it is completely cooked and crushes it up with crude garlic, dalle chilies - amazingly fiery neighbourhood chilies that have a recognizable citrus fruitiness - and liberal lumps of delicate Chhurpi. These are indigenous nourishments privately served at homestay with great taste (Home-prepared food utilizing natural fixings from their nursery). Toward the beginning of the day, the receiving family serves a full cup of tea (Raghavan, 2016).

Momo (Veg. / Non-Veg.) has already entered commercial production and is well placed in menus of local hotels and restaurants. Steamed dumpling prepared from wheat flour and meat or vegetable, is a very common Tibetan food. A special steamer locally called Moktu is required. Filled-up dumplings are placed on oiled racks, slightly separated in the Moktu. They are eaten with meat or vegetable soup, dipped in tomato achar(Jyoti Prakash Tamang \& Thapa, 2014).

This food (Thukpa or Gya-Thuk) Tibetan-style noodle soup. Thukpa or Gya-Thuk is a very popular local dish that is also available in all restaurants and hotels in these regions. Food be tried while staying at homestay in the Indian state of Sikkim. The dish is a flavourful noodle soup, which can be served in both vegetarian and nonvegetarian dishes. The dish originates in the eastern parts of Tibet.

Dhindo is a Sikkim food claim to fame that is very well known among the homestay, local people and travellers. The dish starts from Nepal, however is a serious fury in numerous pieces of Sikkim. The flour is customarily arranged from buckwheat or millet. Grains like wheat and corn flour are basic too. One can utilize practically any grain given that it is pounded into flour. The utensils utilized for its planning is normally an Iron dish called Palame Tapke and an Iron spatula or spoon called the Dabilo. The last helps mix the blend and bring to creation a scrumptious solace dinner that practically all Sikkimese populace love (Upasana, 2020).

Phagshapa is a dish for the summers, this is a pork based dish presented with rice at homestay. Food from Sikkim is for the most part respected to be zesty and despite the fact that this dish contains a considerable amount of warmth, it is as yet simpler on the sense of taste than the rest. The star of the dish is the pork, cooked with unpretentious flavours, bean stew and radish in oil. The pork fat is left on the meat to give it the dish's essential flavour.

Chaang In the severe virus winters of Sikkim, it is perfect to evaluate a mixed refreshment to keep you warm. A Tibetan beverage later embraced by the state, Chaang is an absolute necessity attempt drink in the province of Sikkim. It is created with matured grains and tasted through a bamboo vessel with a bamboo straw. The vessels with the millets are finished off with warm water to separate the flavour.

Kinema Curry an exceptional dish, the star element of this dish is aged soya bean. It is one of the most famous dishes of the state for its taste just as its high protein esteem. A tadka of turmeric powder, onion, red bean stew and tomatoes is added to the sauce to additionally upgrade the taste. The dish is presented with rice. This is an incredible nourishment for the vegans visiting the state at homestay.

Kodo KO Roti a Nepali dish, Kodo KO roti has been received through Sikkim as its very own dish. The dish is a straight forward bread dinner, commonly gave pickle. With Kodo flour or finger millet flour, the player is kneaded and spread over a banana leaf. The leaf is then made sure about and arranged on a tawa. The dish is known to taste best when a tomato pickle is filled in as a reinforcement.

Sael Roti Suggestive of a delicate pretzel as a result of its ring shape, a Sael roti is a bread arranged during celebrations in Nepal. This has been roped in Sikkimese food. The dish is produced using a hitter of aged rice and afterward southern style. The dish is ideal for veggie lovers and non-vegans the same, since it tends to be eaten with a potato curry or even a meat backup.

Gundruk and Sinki are matured vegetable dishes. Green vegetables are pressed into hermetically sealed compartments to make Gundruk. Different vegetables including turnip, radish and mustard are sliced and matured to make the Sinki. They can be eaten or even included into soups, pickles and curries (Iyer, 2016).

Chambray is run of the mill Nepali-type pulao rice arranged from neighbourhood assortments of rice. It is set up by dousing rice with cove leaves and cinnamon for 20 minutes. To begin with, ghee is warmed in a wok, at that point all fixings are included; next, splashed rice is included, and the blend is seared for 5 minutes until the ghee isolates. Water is poured in gradually, and the dish is left to stew until the rice is cooked. Chambray is eaten with tikoalu.

Gya Kho It is one of the indigenous Stack soup served in the soup bowl, and since the bowl resembles the state of a fireplace, it got its name Smokestack soup. This Tibetan food is received by Sikkim (homestay) due to its boundless flavour (Das et al., 2016). 
Bhat-Dal-Tharkari-Achar This is a conventional food from the Indian subcontinent, well known in numerous regions of Nepal, Bangladesh and India. (rice-vegetable soup-curry-pickle) that is a mix of bubbled rice and lentil soup. In numerous pieces of India, it is otherwise called Dal Chawla. It is the ordinary dish of Sikkim individuals that is presented with vegetable curry or meat and chutney (Upasana, 2020).

Pakku is an exemplary sheep curry of this locale which is presented with cooked rice or Selroti. Marinate sheep pieces with the glue, include salt and turmeric powder and save for $20 \mathrm{~min}$. Fry in palatable oil and cook for an hour in low warmth. Serve hot with cooked rice or Selroti. (Jyoti Prakash Tamang et al., 2007).

\section{Objectives of the Study:}

1. To assess the level of awareness about indigenous food of Sikkim among the homestay visitors

2. To assess the preference of indigenous food of Sikkim among the homestay visitors

\section{Scope of the Study:}

This study is focused on the homestay visitors, who visited the homestay and experienced the test of indigenous foods and beverages of Sikkim. Only some of the selected indigenous foods and beverages are covered in the present study.

\section{Research Methodology:}

The examination strategy is the efficient, hypothetical investigation of the techniques applied to a field of study (Kothari, 2004). It includes systems of portraying, clarifying and foreseeing marvels (Kenpro, 2012). The present study is a descriptive and based on the primary data. Primary data is collected through Google form (online survey due to COVID-19 pandemic) between the months of July-August 2020. Questionnaires, 5-point likert type scale 1-5 where 1 means dislike and 5 means like). Secondary data's are not used for this study. For the questionnaires validation normality test and scale reliability are measured by the process of Cronbach's alpha (STATA 11).

\section{Research Design:}

Exploration configuration is comprising the plan or the guide for the assortment, estimation, and investigation of information. As per Kothari (2004), research configuration is an arrangement, a guide and outline procedure of examination considered in order to get answers to investigate questions (Kenpro, 2012).The present study included a survey on the basis of stratified purposive sampling taking strata indigenous food. Researcher purposely distrusted 100 questionnaires to the respondents, who visited homestay of Sikkim. Unrestricted, nonprobability convenience sampling technique has been applied in the research study. Questioners were prepared on the basis of the objectives, and whole analysis based on descriptive and analytical statistics as per the need of the study.

\section{Results and Discussions}

\section{Demographic information of the Respondents:}

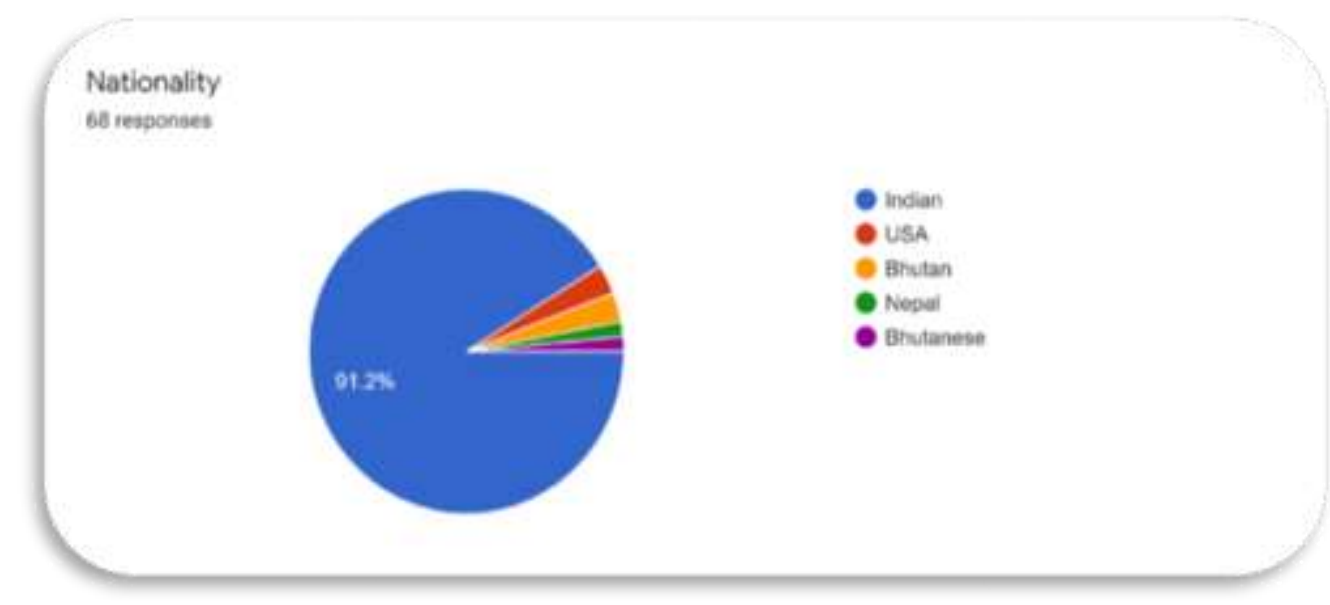

Figure (1): Nationality 


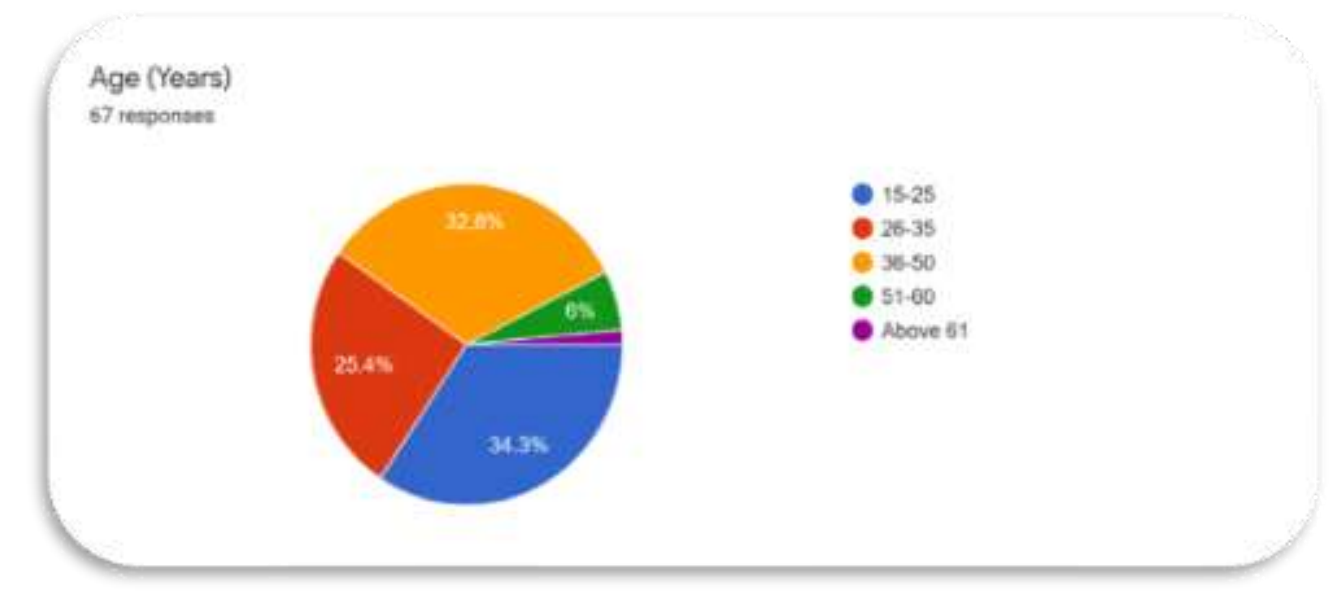

Figure (2): Age

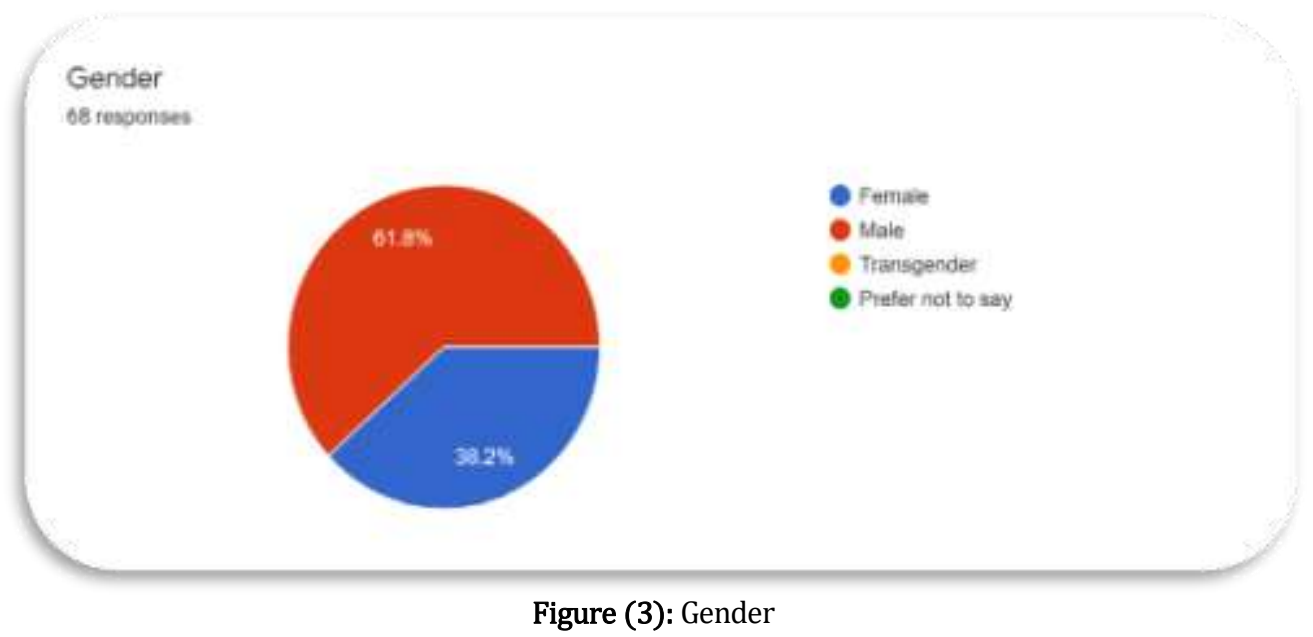

Out of Hundred respondents sixty -eight questionnaires were received back through the Google form, (respondent's percentage rates presented 68\%). The above Figure (1) can be seen, most of the respondents were from India 91.2\% and Bhutan 4.4\%, USA (United State of America) 2.1\%, Nepal 1.5\% very least. On the analysis of demographic data's, presented that, internationally respondents were minimum. Therefore, logistics expansion and promotional activities are needed at the global level by adopting various modes and channels.

The Figure (2) can be seen, most of the respondents were young, in 15-25 age group 34.3\%, 36-50 age group 32.8\%, 26-35 Age group 25.4\%, 51-60 age group 6\% and above 61 age group only 1.5\% flow of the respondents were more in young age group. Here geographical location, activities and accessibility in terms of logistics for Sikkim is one factor. The figure (3) shows in this study male respondents were $61.8 \%$ and female respondents were $38.2 \%$. Here females are least but equally interested.

\section{Demographic details of the Homestay of Sikkim}

\section{Location of the Homestay}

68 mroponses
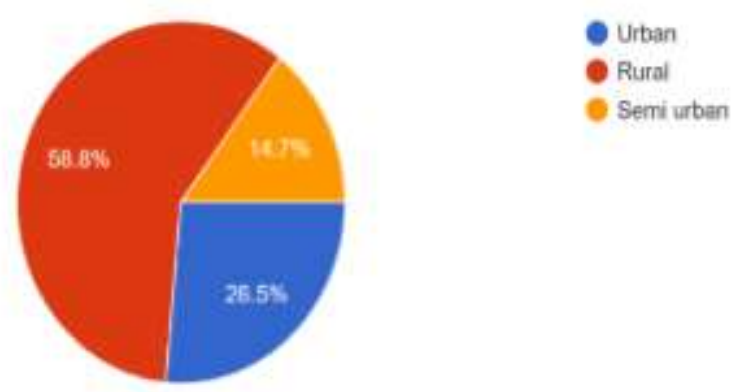

Figure (4): Location of the Homestay 
District of the Homestay Establishment 68 renponses

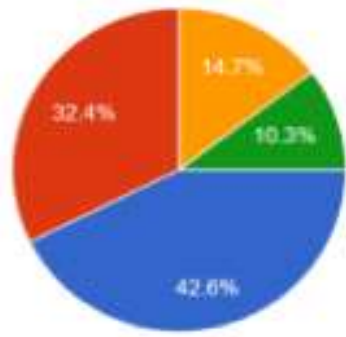

East Sincim

- West Sakim

North Sscoin

- Scuth sakim

Figure (5): District of the Homestay Establishment

The above Figure (4) shows the location of homestay is equally interesting to visit among the respondents. Where rural location was preferred more among the respondents (58.8\%) and urban locations (26.5\%) and Semi urban (14.7\%) were least. Because more rural location indicates authenticity of homestay and their indigenous people, culture, food and many more other activities. The Figure (5) shows the district of the homestay establishments were equally motivating to respondents. Here in study compared district wise respondents, where respondents were visited more to East Sikkim (42.6\%), West Sikkim (32.4\%), and North Sikkim (14.7\%), South Sikkim (10.3\%) was least. Because of more accessibility in east Sikkim and head quarter of Sikkim too.

\section{Selected Indigenous food and beverage of Sikkim awareness among the respondents (in percentage)}

\section{Awareness of Indigenous Food \&amp; Beverage of Sikkim}

68 responses

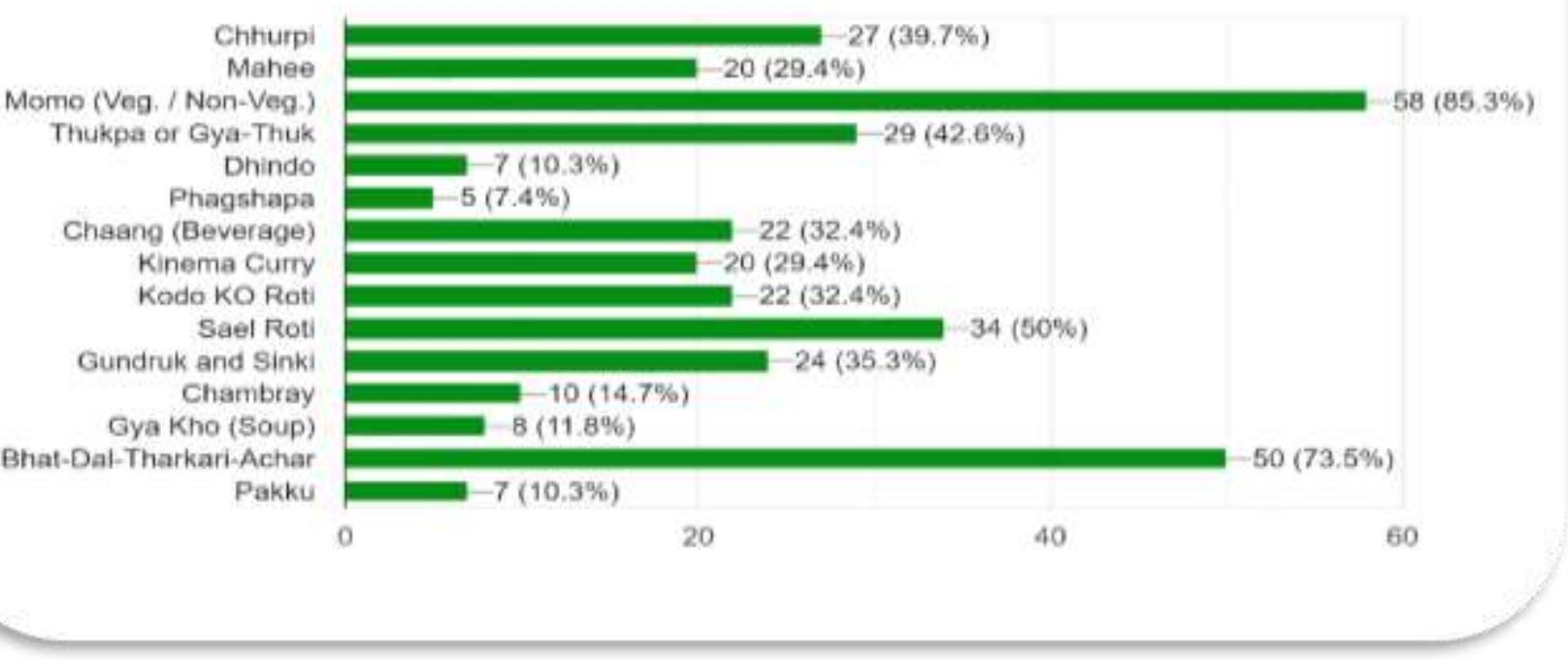

Figure (6): Awareness of Indigenous Food \& amp; Beverage of Sikkim

The above study shows (Fig 6) that, most of the respondents were un-aware about the indigenous food and beverage of Sikkim, which was served at homestay among the respondents. At the same time it was also found that the food of Sikkim (Homestay) was acceptable to the respondents. On further analysis researcher was found that Momo Veg/Non-Veg (85.3\%) and Bhat Dal Tharkari Achar (73.5\%) were highly recognised as an indigenous food of Sikkim among the respondents, Sael Roti (50\%) and Thukpa (42.6\%) was identified among the respondents, and other listed foods and beverages were least recognised. 


\begin{tabular}{|c|c|c|c|c|c|c|c|c|c|c|c|c|c|c|c|}
\hline \multirow[b]{2}{*}{ 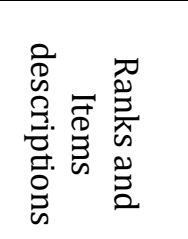 } & 1 & 2 & 3 & 4 & 5 & 6 & 7 & 8 & 9 & 10 & 11 & 12 & 13 & 14 & 15 \\
\hline & 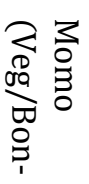 & 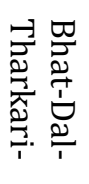 & $\begin{array}{l}u \\
0 \\
0 \\
0 \\
0 \\
0 \\
\Xi .\end{array}$ & 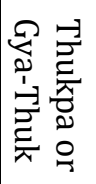 & . & 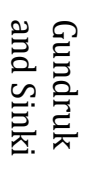 & 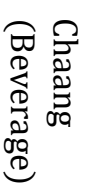 & 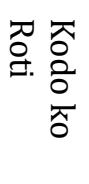 & $\begin{array}{l}3 \\
\frac{3}{0} \\
\frac{0}{0} \\
0\end{array}$ & 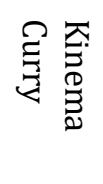 & 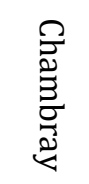 & 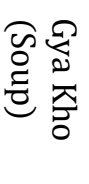 & 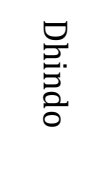 & $\frac{\widetilde{J}}{\frac{D}{X}}$ & 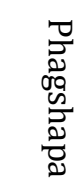 \\
\hline $\begin{array}{c}\text { Awareness } \\
\%\end{array}$ & & & 50 & 42.6 & 39.7 & 35.3 & 32.4 & 32.4 & 29.4 & 29.4 & 14.7 & 11.8 & 10.3 & 10.3 & 7.4 \\
\hline $\begin{array}{c}\text { Not Aware } \\
\%\end{array}$ & 14.7 & 26.5 & 50 & 57.4 & 60.3 & 64.7 & 67.6 & 67.6 & 70.6 & 70.6 & 85.3 & 88.2 & 89.7 & 89.7 & 92.6 \\
\hline Total \% & 100 & 100 & 100 & 100 & 100 & 100 & 100 & 100 & 100 & 100 & 100 & 100 & 100 & 100 & 100 \\
\hline
\end{tabular}

Table (1): Complied by Researcher from original sources Figure (6)

Results are shown in above table 1 that, respondents were un-aware about all the indigenous food and beverage of Sikkim. On further analysis it was also found that, Momo, Bhat-Dal-Tharkari-Achar and Sael Roti were highly recognised among the all foods by respondents. At the same time most of the foods ware least identified (57.4\% to $92.6 \%)$ by the respondents. Therefore, indigenous food and beverage should be promoted (various food festival) by Homestay operators, Gram Panchayat, other agencies and tourism and civil aviation department government of Sikkim. Among the homestay visitors, least recognised foods and beverages should be offered and promoted by the host families during their visit in homestay or in any other festivals and events.

\section{Reliability of the questionnaire:}

The reliability of the questionnaire was framed and measured by normality test from table number 2 to 8 presented below. The present study reliability was measured in all segments.

\begin{tabular}{|ccc|ccc|}
\hline $50 \%$ & Mean 3.382353 & $50 \%$ & Mean 3.426471 \\
\hline & Largest $\quad$ Std. Dev. 1.526184 & & Largest Std. Dev. 1.385599 \\
\hline $90 \%$ & Variance $\quad 2.329236$ & $90 \%$ & Variance & 1.919886 \\
\hline $95 \%$ & Skewness $\quad-.5110033$ & $95 \%$ & Skewness & -.3891541 \\
\hline $99 \%$ & Kurtosis $\quad 1.799306$ & $99 \%$ & Kurtosis & 1.955494 \\
\hline & Table 2 & & & Table 3 \\
\hline
\end{tabular}

\begin{tabular}{|lll|}
\hline $50 \%$ & Mean & 3.323529 \\
\hline & Largest & Std. Dev. 1.500658 \\
\hline $90 \%$ & Variance & 2.251975 \\
\hline $95 \%$ & Skewness & -.4304633 \\
\hline $99 \%$ & Kurtosis $\quad 1.743497$ \\
\hline \multicolumn{3}{|c|}{ Table 4} \\
\hline
\end{tabular}

\begin{tabular}{|lll|}
\hline $50 \%$ & Mean & 3.411765 \\
\hline & Largest & Std. Dev. 1.55722 \\
\hline $90 \%$ & Variance & 2.424934 \\
\hline $95 \%$ & Skewness & -.4915533 \\
\hline $99 \%$ & Kurtosis & 1.746807 \\
\hline & & Table 5 \\
\hline
\end{tabular}

\begin{tabular}{|ccc|}
\hline $50 \%$ & Mean & \multicolumn{1}{l|}{3.352941} \\
\hline & Largest & Std. Dev. 1.443097 \\
\hline $90 \%$ & Variance & 2.082529 \\
\hline $95 \%$ & Skewness & -.4539319 \\
\hline $99 \%$ & Kurtosis & 1.8538 \\
\hline & & Table 6 \\
\hline
\end{tabular}

\begin{tabular}{|lll|}
\hline $50 \%$ & Mean & 3.308824 \\
\hline & Largest & Std. Dev. 1.547818 \\
\hline $90 \%$ & Variance & 2.395742 \\
\hline $95 \%$ & Skewness & -.3070181 \\
\hline $99 \%$ & Kurtosis & 1.615375 \\
\hline & & Table 7 \\
\hline
\end{tabular}




\begin{tabular}{|lll|}
\hline & Mean & 3.573529 \\
\hline & Largest & Std. Dev. 1.459055 \\
\hline $90 \%$ & Variance & 2.128841 \\
\hline $95 \%$ & Skewness & -.6546855 \\
\hline \multicolumn{3}{c}{ Kurtosis } \\
\hline & Table 8 & 2.067001 \\
\hline
\end{tabular}

Here, percentage (\%) indicated total percentage of the respondents. Above all tables were (1 to 8) shown different mean, some standard deviation, variance value and Skewness and kurtosis values are not equals to zero (0), therefore data set shown non-normality. As guest preferences and awareness towards indigenous food and beverage of Sikkim in homestays were varied from person to person. All the tables presented in the different capacities, where table 2 presents the indigenous food in uniqueness, table 3 the consistency in test and aroma of indigenous food, table 4 the food temperature during serving time, table 5 the food freshness, table 6 the food spiciness, table 7 the food value for money and table 8 my interest in indigenous food and beverage of Sikkim at homestay.

\section{The scale reliability test:}

\begin{tabular}{|lc|}
\hline \multicolumn{2}{|l|}{ Test scale $=$ mean (unstandardized items) } \\
\hline Average inter item covariance: & 1.936379 \\
\hline Number of items in the scale: & 5 \\
\hline Scale reliability coefficient: & 0.9796 \\
\hline & Table 9 \\
& \\
\hline
\end{tabular}

The table 9 shows the scale reliability test, and Cronbach's alpha analysis was observed that scale given by researcher was highly significant, as it value shown greater than 0.6 (Scale reliability coefficient: 0.9796).

\section{Preference of Indigenous food among the respondents:}

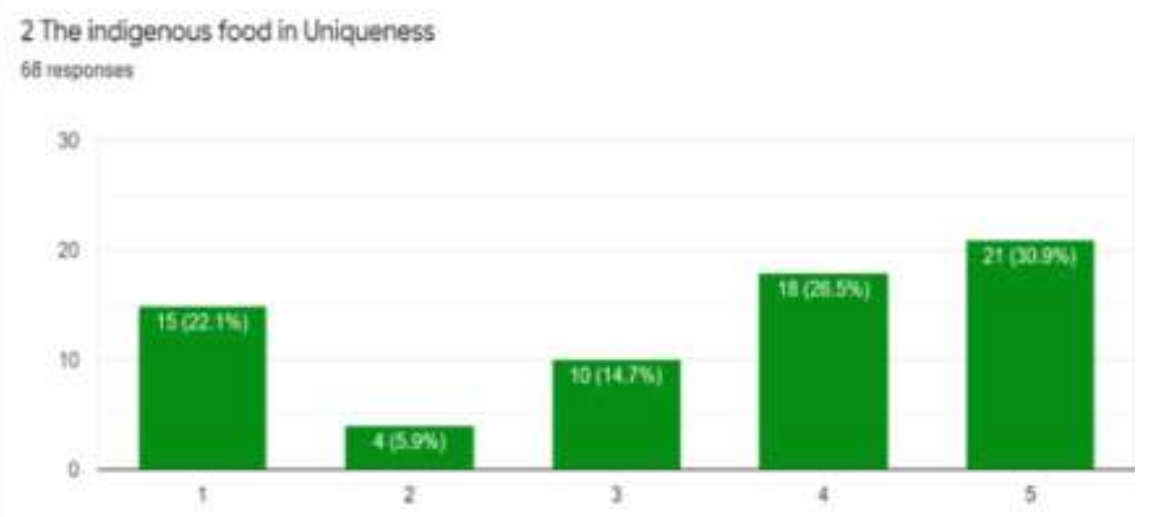

Figure (7): The indigenous Food in Uniqueness

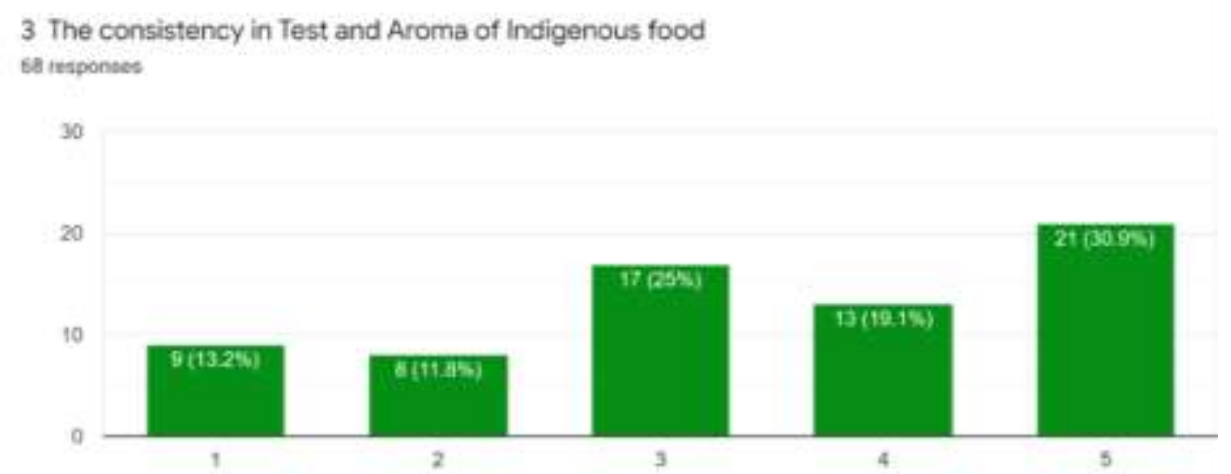

Figure (8): The consistency in Test and Aroma of indigenous Food 


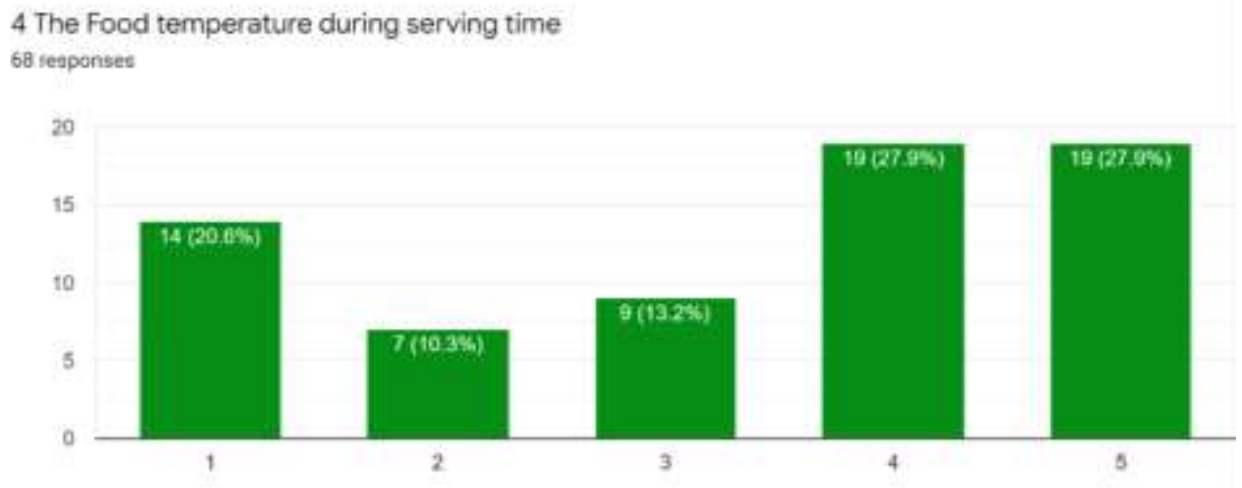

Figure (9): The Food temperature during serving time

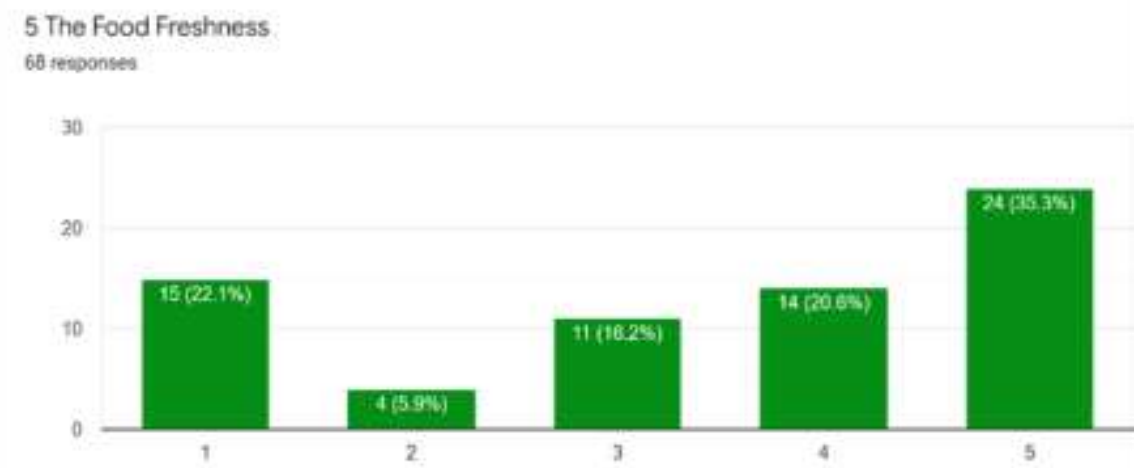

Figure (10): The Food Freshness

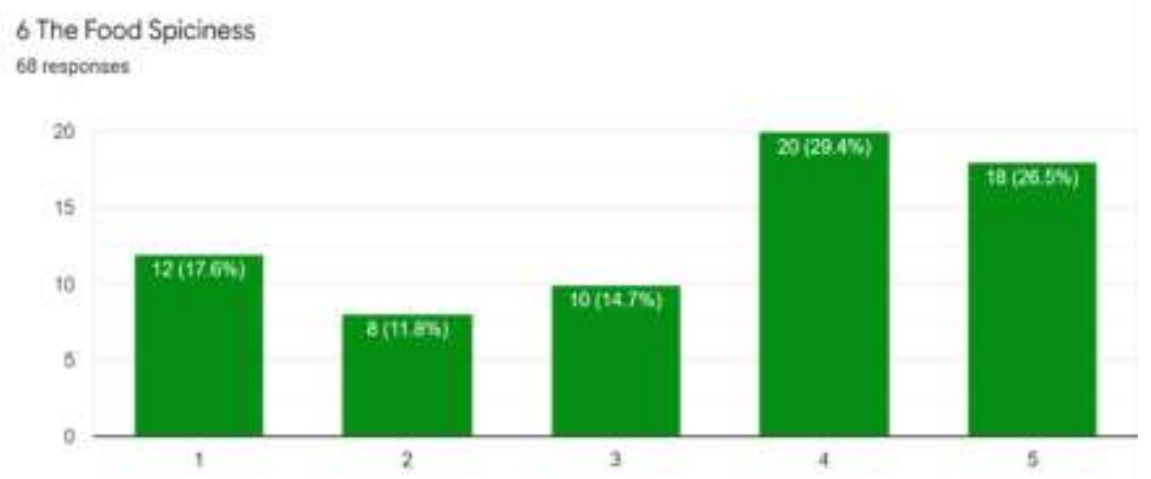

Figure (11): The Food Spiciness 


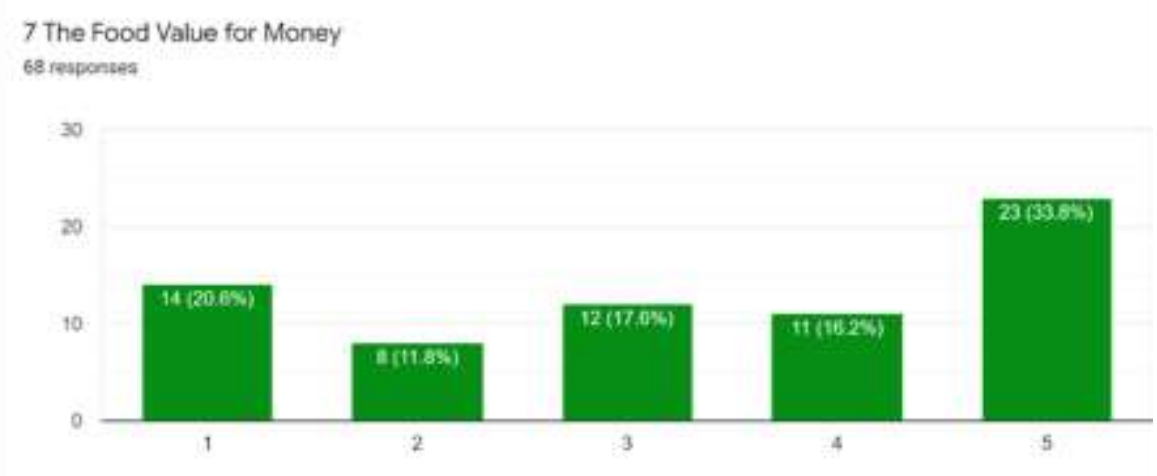

Figure (12): The Food Value for Money

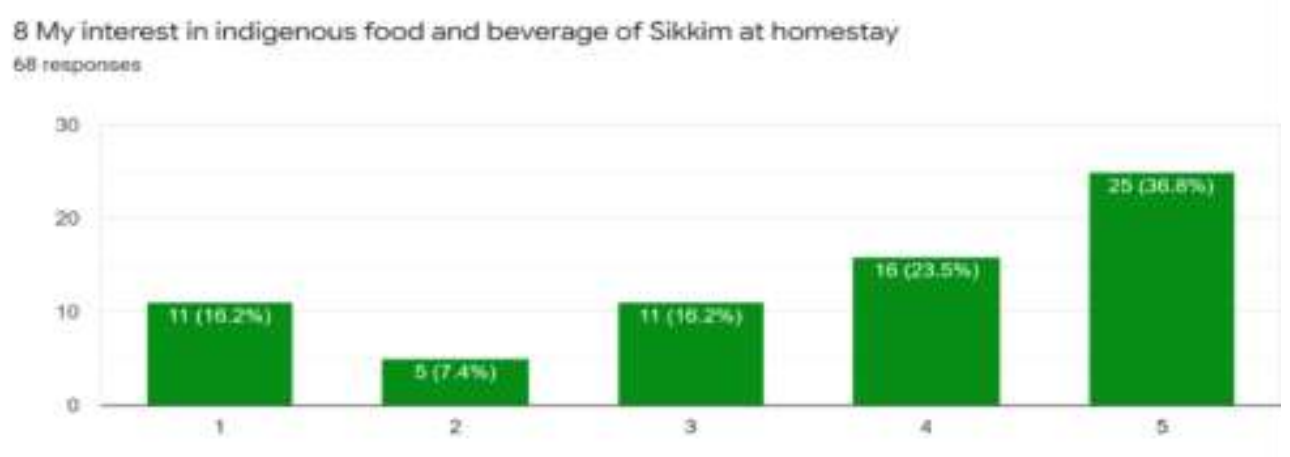

Figure (13): My interest in indigenous food and beverage of Sikkim at homestay

The preference level of the Indigenous food and beverage of Sikkim as per the respondents shown in the figure of (7 to 13) The selected attributes for indigenes food and beverage of Sikkim in homestay, were uniqueness, test, aroma, temperature, freshness, spiciness, value for money and interest, and Likert scale used, where 1(dislike) to 5 (like). Above Figure (7) shown that respondents were like the uniqueness (30.9\%) of indigenous food, served at homestay during the visit. At the same time researcher founded that, food uniqueness, because of organic farming in Sikkim, and local ingredients were used during cooking as per their cooking methods. Figure (8) shown that, respondents were like the test and aroma (30.9\%) of indigenous food. Because of Sikkim organic herbs, food and beverage recipe. As, Sikkim has end numbers of aromatic herbs and spices, which are used in cooking by host family. Figure (9) shows that, respondents were prefer the temperature of food and beverage (27.9\%) during the service time at homestay. Study also presented that, foods were served on proper temperature and on time to the respondents. At the same time homestay visitors/guests were received opportunity to enjoy the foods along with host family members. Figure (10) shows that, (35.3\%) the food freshness was preferred by respondents. The study directed that, during the cooking fresh row materials and ingredients were used. At homestay no concept like hotel to keep row materials and cooked foods in frieze/store for log time, and Sikkim has organic farming in and around of homestay, where guest gets opportunity to go in field and collect food row materials. Figure (11) shows that, (29.4\%) food spiciness was preferred by the respondents, which is below like means visitors were not preferred much spicy food. The respondent was from mixed group and not aware about all the indigenous herbs and spices of Sikkim too. At the same time less spicy food sown health conscious toward the indigenous foods of Sikkim among the respondents. Figure (12) shows (33.8\%) value for money towards the foods. Foods and beverages (served) were value for money among the respondents, because food portion size, service and many more factors were as per the exception of homestay visitors (respondents). Figure (13) shows (36.8\%) that respondents were interested towards the indigenous food and beverage of Sikkim. In this study respondents were shown interest towards homestay, foods and beverages products, local hospitality and all the factors which were mentioned in figure (7 to 13).

\section{Managerial Implication(s)}

Application of the study is dedicated to Homestay sector of Sikkim, where all the homestay has uniqueness in terms of blend of cusine and local hospitality. To publicize the indigenous foods among the all visitors, national/international food festival or mela \& local food \& wine library will be organized by the authority. Advancement of homestay stakeholder skills, proper training will be organized by The Tourism \& Civil Aviation 
Department Government of Sikkim (hospitality/homestay division) at the local level. Design a local (Indigenous) food bazar and outlet in all districts (tourist point) will be planned by the government of Sikkim and formulate some policy (stander operating procedures) to operate (Fortnight or Sennight basis), where stakeholders will be intermingling with all visitors. The outlet/food bazar and homestay operator's will be guided for proper uniform and product knowledge for the advancement of indigenous food and beverage of homestay.

\section{Conclusion(s)}

Since 1600s there has been continuous immigration of the people from neighbouring state of India and other countries like Nepal, Tibet and Bhutan, who had several communities within themselves. Therefore, over the period of time foods and beverages (cuisine) in Sikkim has become a fusion of several cultures and communities. Sikkim has their own cooking style, ingredients (Sikkimese foods and beverages) and garnishing of the cooked food, \& it is the greatest to experience them during stay at the homestay, where host family members cooks and serves indigenous food to the guests. The study discovered that most of the respondents were un-aware about the various foods, since Sikkim is potential for tourism. Therefore it is suggested that, The Tourism \& Civil Aviation Department Government of Sikkim (hospitality/homestay division) and stake holders should take an initiative for publicise the indigenous foods among the all visitors, through various modes of promotional activities (national/international food festival or mela \& local food \& wine library). As, Sikkim has no concepts of street foods, therefore it is recommended that, Government should come up with the design a local (Indigenous) food bazar in all districts (tourist point) and formulate some policy to operate (Fortnight or Sennight basis), Where, tourist/guest or other visitors would visit \& enjoy the real test of indigenous foods and beverages. Through this local (Indigenous) food bazar activity opportunity would be more to interact and explore indigenous food and beverage of Sikkim among the guest/tourist \& other visitors. The stake holders (homestay) should also take care the various aspect about hygiene during preparation and service of the food, so that the tourist/guest feels free to eat the indigenous foods without indecision on the grounds of their health concerns.

\section{Acknowledgment(s):}

I would like to express my sincere appreciation to School of Hospitality \& Tourism Studies, SRM University Sikkim, India, and special thanks to Hon'ble Registrar Prof. Ch. Satish Kumar, Dr. Shatrajit Goswami for providing the necessary baseline for this study. I would also like to acknowledge Mr. Nirmal Cinturyt Assistant Director (Homestay/Hospitality) of the Tourism and Civil Aviation Department Government of Sikkim for their support.

\section{References:}

[1] Bureau, T. H. (2019). "Taj enters homestay segment with Ama Trails - The Hindu BusinessLine". The Hindu.

[2] Chaudhary, M., \& Lama, R. (2014). "Community based tourism development" (a case study of sikkim) doctor of philosophy in tourism and hotel management "community based tourism development-A Case Study of Sikkim under my supervision and guidance in the Depertament of Tourism and Hotel". In kurukshetra university, kurukshetra.

[3] Das, G., Patra, J. K., Singdevsachan, S. K., Gouda, S., \& Shin, H. S. (2016). "Diversity of traditional and fermented foods of the Seven Sister states of India and their nutritional and nutraceutical potential: a review. Frontiers in Life Science, 9(4): 292-312. https://doi.org/10.1080/21553769.2016.1249032

[4] Iyer, S. (2016). "What to Eat in Sikkim Beyond Momos and Thukpa". Outlook Traveller, 2016(03.06.).

[5] Jyoti, T., Kiyohito, O. \&, \& Yasuyuki, K. (2010). "Cultural Adaptation of the Himalayan Ethnic Foods with Special Reference to Sikkim , Arunachal Pradesh and Ladakh". Hiamalyan Study Monographs, 11: 177-185.

[6] Kenpro. (2012). "Research Designs And Methodology". Kenya Project. http://www.kenpro.org/research-design-andmethodology/

[7] Puri, A. (2018). "Why homestays are the next big thing in the Indian hospitality market. Cnbctv". https://www.cnbctv18.com/real-estate/why-homestays-are-the-next-big-thing-in-the-indian-hospitality-market935831.htm

[8] Raghavan, A. (2016). "The two lives of chhurpi". The Indian Express.

[9] Raj, B. (2020). "Traditional Sikkim Food \& Beverages". Darjeeling Tourism. https://www.darjeelingtourism.com/darj_0001eb.htm

[10] Sharma, A., \& Prabir, S. (2015). "Microbial diversity in ethno-fermented foods of Indian Himalayan Region". ENVIS Bulletin Himalayan Ecology, 23, 85.

[11] Sharma, S., \& Goswami, D. shatrajit. (2020). "Hospitality Practices in Homestay of Sikkim and Ongoing COVID-19 Operational guidelines". Juni Khyat, 10(7): 24-30.

[12] Tamang, Jyoti P, Sarkar, P. K., \& Hesseltine, C. W. (1988). "Traditional fermented foods and beverages of Darjeeling and Sikkim-a review". Journal of the Science of Food and Agriculture, 44(4): 375-385. https://doi.org/10.1002/jsfa.2740440410 
[13] Tamang, Jyoti Prakash, \& Thapa, N. (2014). "Some nonfermented ethnic foods of Sikkim in India". Journal of Ethnic Foods, 1(1): 29-33. https://doi.org/10.1016/j.jef.2014.11.008

[14] Tamang, Jyoti Prakash, Thapa, N., Rai, B., Thapa, S., Yonzan, H., Dewan, S., Tamang, B., Sharma, R. M., Rai, A., Chettri, R., Mukhopadhyay, B., \& Pal, B. (2007). "Food Consumption in Sikkim with special reference to Traditional Fermented Foods and Beverages: A Micro-level Survey Sikkim Science Society". Supplementary Issue Journal of Hill Research, 20(1).

[15] Tourism \& Civil Aviation Department Sikkim. (n.d.). "State Portal-Sikkim". Retrieved July 25, 2020, from https://sikkim.gov.in/departments/tourism-civil-aviation-department

[16] Upasana, M. (2020). "Local Sikkim Food Options You Can Enjoy In 2020". https://traveltriangle.com/blog/sikkim-food/

[17] V, K. (2007). "Indigenous Peoples in the CINE Food Systems for Health Program", (pp. 1-7). 